\title{
Correction to: Quantitative Systems Pharmacology Modeling of Avadomide-Induced Neutropenia Enables Virtual Clinical Dose and Schedule Finding Studies
}

\author{
Roberto A. Abbiati, ${ }^{1,6}$ Michael Pourdehnad, ${ }^{2}$ Soraya Carrancio, ${ }^{3}$ Daniel W. Pierce, ${ }^{3}$ Shailaja Kasibhatla, ${ }^{3}$ \\ Mark McConnell, ${ }^{4}$ Matthew W. B. Trotter, ${ }^{1}$ Remco Loos, ${ }^{1}$ Cristina C. Santini, ${ }^{5}$ and Alexander V. Ratushny ${ }^{4,6}$
}

The AAPS Journal volume 23, Article number: 103 (2021)

$$
\text { https://doi.org/10.1208/s12248-021-00623-8 }
$$

The original article has been updated to add the correct supplementary material.

The original has been corrected.

Publisher's Note Springer Nature remains neutral with regard to jurisdictional claims in published maps and institutional affiliations.

The online version of the original article can be found at https:// doi.org/10.1208/s12248-021-00623-8

${ }^{1}$ Bristol Myers Squibb, Center for Innovation and Translational Research Europe (CITRE), Seville, Spain.

${ }^{2}$ Bristol Myers Squibb, San Francisco, California, USA.

${ }^{3}$ Bristol Myers Squibb, San Diego, California, USA.

${ }^{4}$ Bristol Myers Squibb, Seattle, Washington, USA.

${ }^{5}$ Roche Pharma Research and Early Development, Pharmaceutical

Sciences, Roche Innovation Center, Basel, Switzerland.

${ }^{6}$ To whom correspondence should be addressed. (e-mail: roberto.abbiati@bms.com; alexander.ratushnyy@bms.com) 